einstein

Official Publication of the Instituto Israelita

de Ensino e Pesquisa Albert Einstein

ISSN: 1679-4508 | e-ISSN: 2317-6385

\title{
Biomechanical comparison of
} plantar-to-dorsal and dorsal-to-plantar screw fixation strength for subtalar arthrodesis

\author{
Comparação biomecânica da força de fixação de \\ parafuso com orientação de plantar para dorsal e \\ vice-versa para artrodese subtalar
}

\begin{abstract}
Nileshkumar Chaudhari', Alexandre Leme Godoy-Santos ${ }^{2.3}$, Cesar de Cesar Netto4, Ramon Rodriguez ${ }^{5}$, Shouchen Dun ${ }^{1}$, Jun Kit He ${ }^{1}$, Haley McKissack', Glenn S. Fleisig ${ }^{6}$, Eduardo Araujo Pires², Ashish Shah ${ }^{1}$

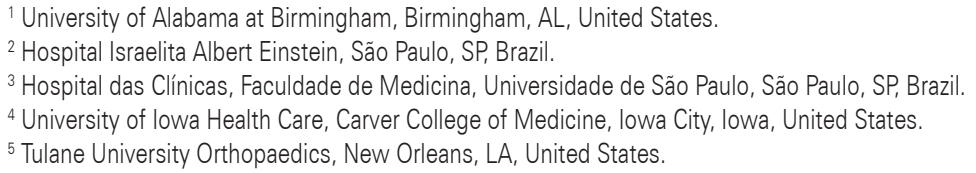

DOI: 10.31744/einstein_journal/2020A05052

\section{ABSTRACT}

Objective: To compare screw fixation strength for subtalar arthrodesis. Methods: Eight matched pairs of cadaver feet underwent subtalar joint arthrodesis with two 7.3mm cannulated screws. Randomization was used to assign screw orientation, such that one foot in each pair was assigned dorsal to plantar screw orientation (DP Group), and the other foot, plantar to dorsal orientation (PD Group). Standard surgical technique with fluoroscopy was used for each approach. Following fixation, each specimen was loaded to failure with a Bionix ${ }^{\circledR} 858$ MTS device, applying a downward axial force at a distance to create torque. Torque to failure was compared between DP and PD Groups using Student's $t$ test, with $p=0.05$ used to determine statistical significance. Results: Statistical analysis demonstrated that the mean torque to failure slightly favored the DP Group (37.3Nm) to the PD Group (32.2Nm). However, the difference between the two groups was not statistically significant $(p=0.55)$. Conclusion: In subtalar arthrodesis, there is no significant difference in construct strength between dorsal-to-plantar and plantar-to-dorsal screw orientation. The approach chosen by the surgeon should be based on factors other than the biomechanical strength of the screw orientation.

Keywords: Subtalar joint; Arthrodesis; Ankle; Joint instability; Arthritis; Joint diseases

\section{RESUMO}

Objetivo: Comparar a força de fixação dos parafusos para artrodese subtalar. Métodos: Oito pares de pés de cadáveres frescos foram submetidos à artrodese da articulação subtalar com dois parafusos canulados de 7,3mm. A randomização foi usada para atribuir a orientação do parafuso, de modo que um pé em cada par foi designado com orientação de dorsal para plantar (Grupo DP), e o outro pé com orientação de plantar para dorsal (Grupo PD). Técnica cirúrgica padrão com radioscopia foi usada para os procedimentos. Após a fixação, cada amostra foi testada até a falha com um dispositivo Bionix ${ }^{\circledR} 858$ MTS, aplicando força axial descendente a uma distância para criar torque. 0 torque de falha foi comparado entre os Grupos DP e PD, usando o teste $t$ 
de Student, com $p=0,05$ usado para determinar significância estatística. Resultados: A análise estatística demonstrou que a média do torque até a falha favoreceu ligeiramente o Grupo DP $(37,3 \mathrm{Nm})$ em relação ao $\mathrm{PD}(32,2 \mathrm{Nm})$. No entanto, a diferença entre os dois grupos não foi estatisticamente significativa $(p=0,55)$. Conclusão: $\mathrm{Na}$ artrodese subtalar, não há diferença significativa na força de compressão entre as orientações dos parafusos dorsalplantar e plantar-dorsal. A abordagem escolhida pelo cirurgião deve ser baseada em outros fatores, sem preocupação com a força biomecânica da orientação dos parafusos.

Descritores: Articulação subtalar; Artrodese; Tornozelo; Instabilidade articular; Artrite; Artropatias

\section{INTRODUCTION}

Arthrodesis of the subtalar joint is an effective treatment for patients with isolated subtalar arthritis or instability. ${ }^{(1,2)}$ Subtalar joint arthritis may develop idiopathically or secondary to trauma $^{(3)}$ inflammatory arthropathy, ${ }^{(4)}$ tarsal coalition, ${ }^{(5)}$ and ankle arthrodesis. The subtalar joint may become unstable by ligament or tendon insufficiency, ${ }^{(6,7)}$ or by neuromuscular dysfunction. ${ }^{(8)}$ Subtalar arthrodesis is done as a component of triple arthrodesis for stage three adult-acquired flat foot to correct hind foot misalignment. However, for talocalcaneal conditions, isolated subtalar arthrodesis has also been advocated for with cited advantages of lower risk of adjacent joint arthritis and lower risk of nonunion or malunion of the transverse tarsal joint. In all cases the procedure is performed to relieve pain and improve function. ${ }^{(1,2,9)}$ The root of this pain lies in changes in articular geometry and, therefore, joint motion, in these pathologies. There is increased stress on joints in the area and the foot is forced to perform abnormal motions, resulting in increased contact stress and forces that cause further degeneration. ${ }^{(10)}$ The goal is to fuse the subtalar joint in a solid and physiologic position to stop further painful motion..$^{(11)}$

Fusion rates in subtalar arthrodesis range from $84 \%$ to $100 \%$ in various studies. ${ }^{(1,2,12)}$ Operative techniques have included various adjuncts to help achieve fusion, including autogenous bone graft, allograft, and, more recently, various orthobiologics. ${ }^{(13)}$ Subtalar arthrodesis with autologous bone grafts and secured with cancellous bone screw showed ample stability and rate of union. Prior to 1970, internal fixation was not used for these procedures, particularly in children. Initially, Steinmann pins were used to maintain the achieved position of the joint, and later staples and power devices were used. ${ }^{(14,15)}$ With the advent of $\mathrm{AO}$ techniques (https://www.aofoundation.org/), compression screws were introduced to maintain position and to enhance the likelihood of a successful bony fusion. . $^{(1,9,16,17)}$
The goal of this study was to compare the biomechanical stability of these two constructs, to investigate whether dorsal-to-plantar screw orientation or plantar-to-dorsal screw orientation creates a more stable construct. The techniques were compared using two screws for fixation. From dorsal to plantar, two $32 \mathrm{~mm}$ partially-threaded, $7.3 \mathrm{~mm}$ cannulated cancellous screws were used. From plantar to dorsal, two $7.3 \mathrm{~mm}$ cannulated cancellous screws were used; the shortthreaded $16 \mathrm{~mm}$ screw was used to gain compression in combination with a long-threaded screw to maximize the fixation with this approach.

\section{OBJECTIVE}

To compare screw fixation strength for subtalar arthrodesis.

\section{METHODS}

Eight matched-pair fresh-frozen human cadaver feet were tested for this study at the American Sports Medicine Institute (ASMI), from May to July 2018. This project has exemption from ethics committee (www.birmingham.ac.uk/Documents/university/legal/ research.pdf). The age of the donors was $56( \pm 6.5)$ years old. The specimen was stored frozen at $-20^{\circ} \mathrm{C}$ until the day before testing. Each specimen was thawed overnight at room temperature. All subtalar joint preparations and fixations were performed by a single surgeon.

One foot from each pair was randomly assigned to one of two groups. One group underwent screw placement in the dorsal-to-plantar orientation (DP Group) from the neck of the talus to posterior calcaneus, and the other group from plantar-to-dorsal orientation (PD Group) from posterior calcaneus to the body and neck of talus.

The subtalar joint was exposed through a $2 \mathrm{~cm}$ curvilinear incision starting from the tip of the lateral malleolus, extending distally and anteriorly up to sinus tarsi and then extending distally around $1 \mathrm{~cm}$. The extensor digitorum brevis muscle was elevated along with sinus tarsi fat pad in single thick flap. Cartilage from the subtalar joint was denuded both from the talus and the calcaneus.

For dorsal-to-plantar screw fixation, an approximately $3 \mathrm{~cm}$ incision was made between the tibialis anterior tendon and extensor hallucis longus tendon, starting at the level of the anterior ankle joint and extending distally. The neck, medial, and lateral boundaries of the talus were exposed. The heel was held in the 
center of the palm, maintaining $5^{\circ}$ of valgus at the subtalar joint. One $4.5 \mathrm{~mm}$ threaded guide pin for a $7.3 \mathrm{~mm}$ screw was placed from the center of the neck of the talus directed towards the center of the palm at the posterior inferior aspect of the calcaneal tubercle, to fix the subtalar joint and compress the posterior facet. Image intensification was utilized with a sagittal and a tangential view of the calcaneus to confirm accurate placement of the pin. Another pin was placed from the medial aspect of the talus neck and directed laterally and plantar towards the calcaneus to fix the anterior facet of subtalar joint. Drilling of the talus and superior surface of the calcaneus was carried out after determining the appropriate depth with the gauge. A $7.3 \mathrm{~mm}, 32 \mathrm{~mm}$ thread length cannulated cancellous lag screw was inserted over the pin to tightness. A second guide pin was placed distally and more medially on the talar neck, directed more laterally and plantar into the anterior process of the calcaneus. The second pin was measured and overdrilled and the screw was inserted.

For plantar-to-dorsal screw fixation, an approximately $2 \mathrm{~cm}$ incision was made posteroinferiorly over the calcaneus distal to the Achilles tendon insertion. Two $4.5 \mathrm{~mm}$ threaded guide pins were placed in parallel from the posterior aspect of calcaneus into the body and neck of the talus. Two $7.3 \mathrm{~mm}$ cannulated cancellous screws were placed over the guide pins after drilling across the plantar cortex of the talus. Placement of the screws was confirmed with image intensification, using sagittal and anterior views of the ankle and a tangential view of the calcaneus.

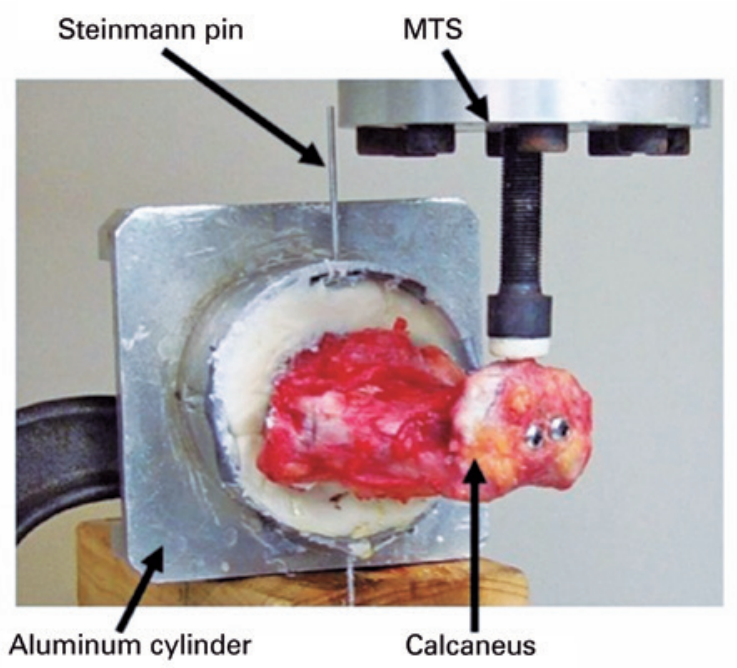

MTS: Bionix 858 MTS.

Figure 1. Experimental setup. The talus is potted within the aluminum cylinder A Steinmann pin is drilled to hold the talus in place. The medial aspects of the talus and calcaneus are facing up
After all the soft tissues were removed from the bones, the talus was potted into an aluminum cylinder using polymethyl-methacrylate (PMMA) (Figure 1). A threaded Steinmann pin was drilled through the holes on the cylinder wall, PMMA, and talus to help hold the specimen in position. The construct was mounted on a material testing system (Bionix ${ }^{\circledR}$ 858, MTS, Eden Prairie, $\mathrm{MN}$ ) with the talus and calcaneus in the horizontal direction and the medial aspects of each facing up (Figure 2). The position of the construct was adjusted so that the vertical load could be applied to the distal point of the medial aspect of the calcaneus, with the tip of the actuator simulating a medially-applied force at the subtalar joint. Vertical load was applied at $5 \mathrm{~mm} / \mathrm{s} .{ }^{(18)}$ The test was terminated when an approximately $5 \mathrm{~mm}$ opening (measured by a tape) at the subtalar joint was observed. The force to failure was determined to be the force at which the fixation failed, which was indicated by a sudden drop in the load-displacement. ${ }^{(6)}$ The distance between the point of force application to the center of the subtalar joint line was measured using a digital caliper (500-196-20 0-6 Digimatic Caliper, Mitutoyo America, Aurora, IL) and served as the moment arm. The product of this moment arm and the force to failure was considered as the screw fixation failure torque.

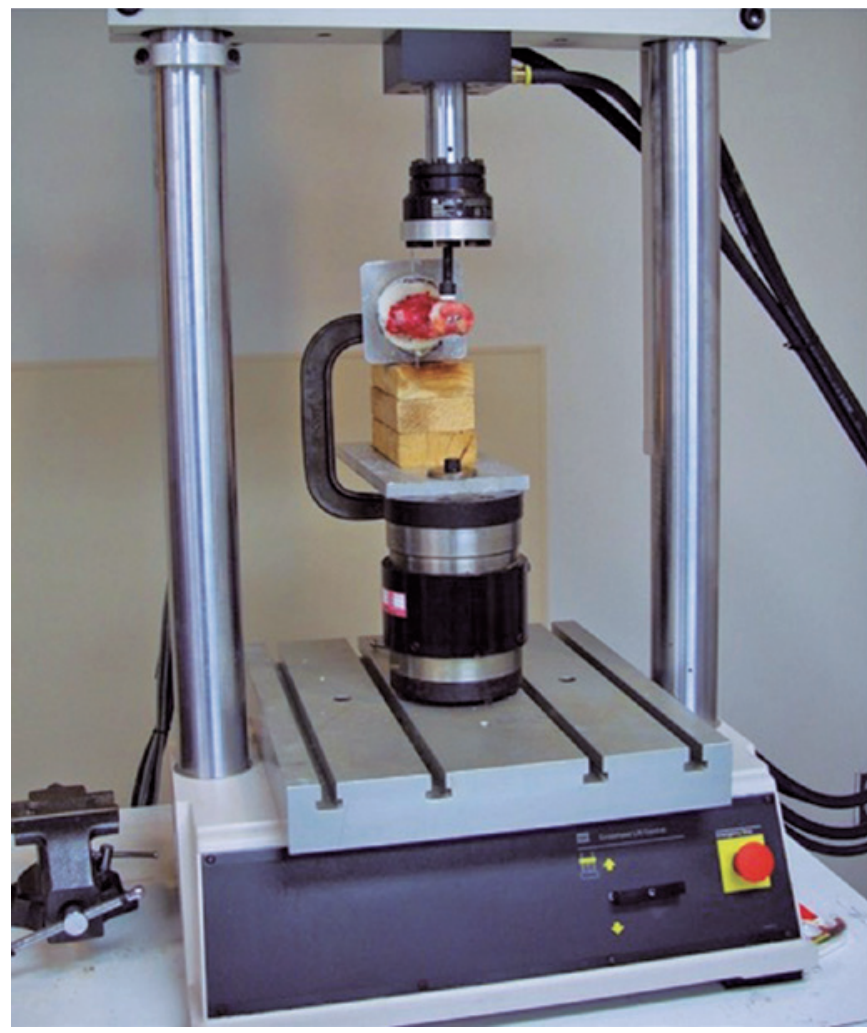

Figure 2. Experimental setup. The construct was mounted on a material testing system 
The fixation strengths were compared between the two groups using a paired $t$ test. Statistical significance was kept at $p<0.05$. Statistical analysis was conducted using (SPSS), version 11.5.0 software (SPSS Inc., Chicago, IL).

\section{॥ RESULTS}

The force to failure was $585.9 \pm 201.1 \mathrm{~N}$ for the plantarto-dorsal fixation and $667.2 \pm 449.4 \mathrm{~N}$ for the dorsal-toplantar fixation. The moment arm was $55.1 \pm 4.7 \mathrm{~mm}$ for the dorsal-to-plantar fixation and $54.8 \pm 3.9 \mathrm{~mm}$ for the plantar-to-dorsal fixation. The failure torque was $32.2 \pm 11.2 \mathrm{Nm}$ and $37.3 \pm 26.9 \mathrm{Nm}$ for the plantar-todorsal and dorsal-to-plantar fixations, respectively (Figure 3 and 4). Even though the average failure torque of the dorsal-to-plantar technique was slightly greater than that of the plantar-to-dorsal technique, the difference was not statistically significant $(\mathrm{p}=0.55)$.

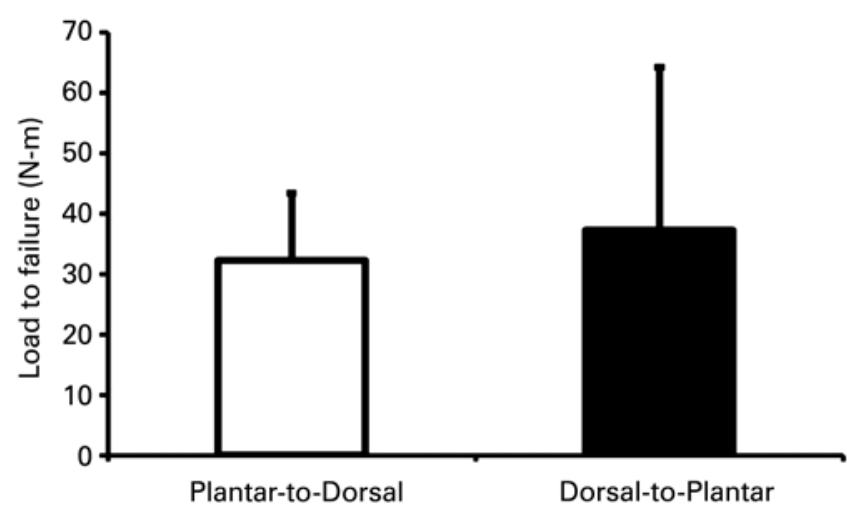

Figure 3. Comparison of load to failure between plantar-to-dorsal and dorsal-toplantar fixations

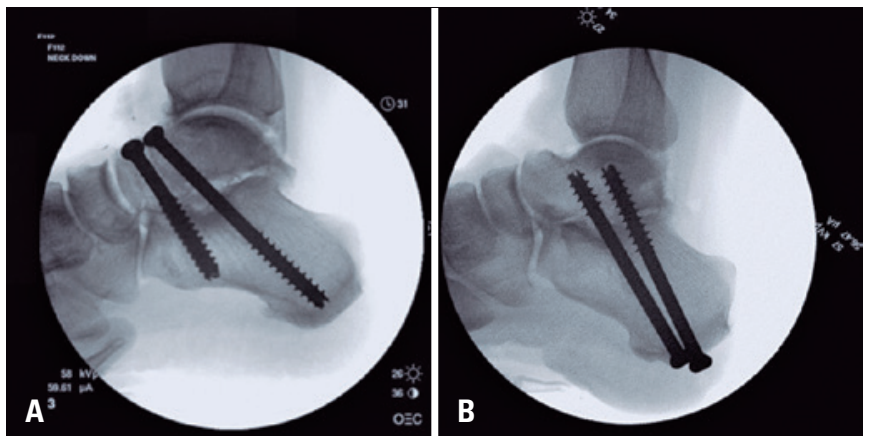

Figure 4. Screw placements. (A) Dorsal-to-plantar screw orientation. Two $7.3 \mathrm{~mm}$ cannulated screws were placed from the talus, directed posteriorly through the calcaneus toward the plantar surface. (B) Plantar-to-dorsal screw orientation. Two $7.3 \mathrm{~mm}$ cannulated screws were directed from the calcaneus, anteriorly and superiorly through the talus

\section{DISCUSSION}

When performing subtalar arthrodesis, internal fixation with screws has been shown to achieve exceptional compression and rigid immobilization. Surgeons have the choice of types of screw, number of screws, and direction of screw placement. ${ }^{(19)}$ There is no consensus on which manner of fixation is the best. ${ }^{(20,21)}$

Rate of nonunion with subtalar arthrodesis has been reported to vary between $2 \%$ and $30 \%$. $^{(22)}$ Meticulous preparation of the joint, compression, and immobilization are especially important for preventing non-union and malunion. ${ }^{(19)}$ The use of double parallel screws and double diverging screws have both been identified to provide support under two to three-fold greater compressive force than a single-screw construct. Chuckpaiwong et al. provided biomechanical evidence for selecting specific screw constructs, trajectories, and patterns. A double screw fixation displayed greater compression, torsional stiffness, and resistance to joint rotation. ${ }^{(23)}$

There is also a positive correlation between bone density and compression capacity of screws. ${ }^{(22)}$ The bone in the neck is harder than the soft cancellous bone of the heel, which gives better purchase to the head. We therefore used the long-threaded $32 \mathrm{~mm}$ screws for better calcaneal stability. ${ }^{(11)}$

Previous literature has not compared the biomechanical effectiveness and fusion rates between placing screw from the heel up and from the talar neck down for internal fixation. Fixation in the plantar-todorsal direction, from calcaneus to talus, has become routine in many practices. ${ }^{(1)}$ This approach is commonly used when performing a calcaneal osteotomy with subtalar fusion, as in rheumatoid arthritis, severe deformity in posterior tibial dysfunction, and in some cases of arthritis secondary to calcaneal fractures. ${ }^{(18)}$ The advantages described are that this technique has an easier initial approach, access to denser talar bone once the screw is placed, and less risk of neurovascular injury than the dorsal-to-plantar approach. ${ }^{(16)}$ Any disturbance of bone supply can easily deprive the bone of the oxygen source, potentially leading to talar avascular necrosis. The plantar-to-dorsal technique avoids this complication. ${ }^{(24)}$

The alleged disadvantages to the heel approach are that the calcaneal cortex is often relatively soft, necessitating use of a washer to stabilize the screw head and prevent penetration, and that the short-threaded screw is needed for at least the first screw to allow compression and avoid the threading from crossing the joint. ${ }^{(11)}$ Additionally it is often cumbersome to the 
surgeon to control foot position in addition to having to hold the foot up in order to place the screws. Consistent with Kunzler et al., a frequent complaint with this technique is symptomatic hardware from prominence of headed screws, occurring from $11 \%$ to $53 \%$ of cases. The patients walk on the screws which elicits pain and the screws often need to be taken out, requiring a return to the operating room. A simple solution to this was the suggested use of headless screws that allow burial below the cortical surface. ${ }^{(25)}$

The dorsal-to-plantar technique has its own benefits and disadvantages as well. When osteotomy of the calcaneus or other indications listed above are not present, this approach allows simple supine positioning of the patient with a bump under the hip to bring the foot to a neutral rotation position, and only two fluoroscopy views are required to check position of the pin. The surgeon can hold the foot in one hand and place the pins and screws with the drill in the other hand in an easily reproducible manner. This also allows the surgeon to manipulate the foot easily, observe the range of motion and relation between the talus and calcaneus, and assess the impact on procedure outcome. ${ }^{(14)}$ By holding the heel in the midpoint of the palm and aiming to this point with the pin through the neck of the talus, accurate placement of this first pin can be frequently achieved on the first try. After this screw is inserted, the first guide pin can be left in place and the second pin can easily be oriented based on the first. ${ }^{(26)}$ In contrast, placing the guide pins from plantar to dorsal requires placing the patient in the lateral position, holding that position with a device such as a vacuum "bean-bag", making certain that the fluoroscopy beam rotation is perfectly sagittal, and acquiring three views to ensure accurate pin placement. ${ }^{(9)}$

One limitation of the dorsal-to-plantar technique is the possibility of anterior ankle impingement on the lower anterior tibia by the hardware, if the screws are not placed deep enough in the talar neck. Limited thread tightness has also been reported in the less dense calcaneal bone. ${ }^{(11)}$ This can be overcome by confirming the depth fluoroscopically and ensuring appropriate range of motion of the ankle after arthrodesis. The surgeon can also solve this by countersinking the screws or placing the screws further down the talar neck if the anatomy allows.

Avascular necrosis is an additional risk to take into consideration with the dorsal-to-plantar technique. It has been reported in the literature that avascular necrosis occurs at the subchondral bone, at the subtalar joint, in a sizeable portion of patients who develop this complication. Of note, the results of this study showed a large standard deviation of $449.4 \mathrm{~N}$ for force failure in the dorsal-to-plantar fixation construct, as compared to 201.1N in the plantar-to-dorsal fixation construct. This variation may suggest that stability using the dorsalto-plantar approach is less predictable; however, no definite conclusion can be drawn and this would warrant further investigation.

In terms of limitations for this study, sample size was small as only eight matched pairs of cadaveric limbs were included. Furthermore, only the strength of the construct was tested in the Bionix 858 MTS, ignoring the other biological factors involved in the successful arthrodesis of the subtalar joint. Additionally, the bone marrow density of the cadaveric bone was unknown, which may impact the overall strength of the constructs. Future studies that account for the factors mentioned above are warranted to compare fusion rates with the dorsal-plantar and plantar-dorsal techniques.

No significant difference was found between the dorsal-to-plantar or the plantar-to-dorsal technique with respect to the failure torque of the screw construct.

\section{CONCLUSION}

Although no definitive conclusions can be drawn with respect to this study's clinical implications, our results suggest that the surgeon may be able to determine the manner of fixation by taking into account additional procedures that need to be accomplished, rather than by which screw orientation will provide the most stable arthrodesis. When subtalar fusion needs to be combined with a calcaneal osteotomy, the screws can be placed from the calcaneus to the talus. If there is no need for an osteotomy, the method is at the surgeon's discretion.

\section{AUTHORS' CONTRIBUTION}

Each individual author contributed individually and significantly to the development of this work. NC: wrote and reviewed the article; ALGS: contributed to the interpretation of data, critical revision; $\mathrm{CCN}$ : contributed to the critical revision; RR: contributed to the acquisition of data, SD: contributed to the interpretation of data; JKH wrote and reviewed the article; HK: collected the data and performed statistical analysis; GSF: collected the data and performed statistical analysis; EAP: contributed to revision and submission; AS: contributed to the interpretation of data, critical revision, and the intellectual concept of the study and the entire research project. 


\section{AUTHORS' INFORMATION}

Chaudhari N: http://orcid.org/0000-0002-9777-7478

Godoy-Santos AL: http://orcid.org/0000-0002-6672-1869

de Cesar Netto C: http://orcid.org/0000-0001-6037-0685

Rodriguez R: http://orcid.org/0000-0002-2130-6450

Dun S: http://orcid.org/0000-0002-1357-6223

He JK: http://orcid.org/0000-0002-1008-7141

McKissack H: http://orcid.org/0000-0001-9260-2807

Fleisig GS: http://orcid.org/0000-0002-9029-8749

Pires EA: http://orcid.org/0000-0001-6008-8671

Shah A: http://orcid.org/0000-0001-5806-9498

\section{REFERENCES}

1. Mann RA, Beaman DN, Horton GA. Isolated subtalar arthrodesis. Foot Ankle Int. 1998;19(8):511-9.

2. Russotti GM, Cass JR, Johnson KA. Isolated talocalcaneal arthrodesis. A technique using moldable bone graft. J Bone Joint Surg Am. 1988;70(10): 1472-8.

3. Canale ST, Kelly FB Jr. Fractures of the neck of the talus. Long-term evaluation of seventy-one cases. J Bone Joint Surg Am. 1978;60(2):143-56.

4. Miehlke W, Gschwend N, Rippstein P, Simmen BR. Compression arthrodesis of the rheumatoid ankle and hindfoot. Clin Orthop Relat Res. 1997;(340):75-86.

5. Cowell HR, Elener V. Rigid painful flatfoot secondary to tarsal coalition. Clin Orthop Relat Res. 1983(177):54-60.

6. Mangone PG, Fleming LL, Fleming SS, Hedrick MR, Seiler JG 3rd, Bailey E. Treatment of acquired adult planovalgus deformities with subtalar fusion. Clin Orthop Relat Res. 1997(341):106-12.

7. Stephens HM, Walling AK, Solmen JD, Tankson CJ. Subtalar repositional arthrodesis for adult acquired flatfoot. Clin Orthop Relat Res. 1999(365):69-73.

8. Santavirta S, Turunen V, Ylinen P, Konttinen YT, Tallroth K. Foot and ankle fusions in Charcot-Marie-Tooth disease. Arch Orthop Trauma Surg. 1993;112(4):175-9.

9. Easley ME, Trnka HJ, Schon LC, Myerson MS. Isolated subtalar arthrodesis. J Bone Joint Surg Am. 2000;82(5):613-24.

10. Valderrabano V, Hintermann B, Nigg BM, Stefanyshyn D, Stergiou P. Kinematic changes after fusion and total replacement of the ankle part 1: range of motion. Foot Ankle Int. 2003;24(12):881-7.

11. Riedl M, Glisson RR, Matsumoto T, Hofstaetter SG, Easley ME. Torsional stiffness after subtalar arthrodesis using second generation headless compression screws: Biomechanical comparison of 2-screw and 3-screw fixation. Clin Biomech (Bristol, Avon). 2017:45:32-7.
12. Flemister AS Jr, Infante AF, Sanders RW, Walling AK. Subtalar arthrodesis for complications of intra-articular calcaneal fractures. Foot Ankle Int. 2000; $21(5): 392-9$

13. Zanolli DH, Nunley JA 2nd, Easley ME. Subtalar fusion rate in patients with previous ipsilateral ankle arthrodesis. Foot Ankle Int. 2015;36(9):10258-8.

14. Yu GV, Brook JW, Ruelle A, Brosky TA. Isolated subtalar joint arthrodesis: refinements in fixation technique. In: Reconstructive Surgery of the Foot and Leg Update '97. Turkey: The Podiatry Institute Inc; 1997. p. 180-91.

15. Haskell A, Pfeiff C, Mann R. Subtalar joint arthrodesis using a single lag screw. Foot Ankle Int. 2004;25(11):774-7.

16. Eichinger M, Schmölz W, Brunner A, Mayr R, Bölderl A. Subtalar arthrodesis stabilisation with screws in an angulated configuration is superior to the parallel disposition: a biomechanical study. Int Orthop. 2015;39(11):2275-80.

17. Shah A, Naranje S, Araoye I, Elattar O, Godoy-Santos AL, Cesar C Netto. Role of bone grafts and bone graft substitutes in isolated subtalar joint arthrodesis. Acta Ortop Bras. 2017;25(5):183-7.

18. Kulkarni GS. Chapter -352 Retrograde Tibial nailing for arthrodesis of ankle and subtalar joints. In: Kulkarni GS, Babhulkar S. Textbook of Orthopedics \& Trauma. 3rd ed. 4 vol. New Delhi, India: Jaypee Brothers Medical Publishers; 2016. p.3449-58.

19. Matsumoto T, Glisson RR, Reidl M, Easley ME. Compressive force with 2-screw and 3-screw subtalar joint arthrodesis with headless compression screws. Foot Ankle Int. 2016;37(12):1357-63.

20. Yuan CS, Tan XK, Zhou BH, Liu JP, Tao X, Tang KL. Differential efficacy of subtalar fusion with three operative approaches. J Orthop Surg Res. 2014; 9:115.

21. Jastifer JR, Alrafeek S, Howard P, Gustafson PA, Coughlin MJ. Biomechanical evaluation of strength and stiffness of subtalar joint arthrodesis screw constructs. Foot Ankle Int. 2016;37(4):419-26.

22. Tuijthof GJ, Beimers L, Kerkhoffs GM, Dankelman J, van Dijk CN. Overview of subtalar arthrodesis techniques: options, pitfalls and solutions. Foot Ankle Surg. 2010;16(3):107-16. Review.

23. Chuckpaiwong B, Easley ME, Glisson RR. Screw placement in subtalar arthrodesis: a biomechanical study. Foot Ankle Int. 2009;30(2):133-41.

24. Pearce DH, Mongiardi CN, Fornasier VL, Daniels TR. Avascular necrosis of the talus: a pictorial essay. Radiographics. 2005;25(2):399-410. Review.

25. Kunzler D, Shazadeh Safavi P, Jupiter D, Panchbhavi VK. A Comparison of removal rates of headless screws versus headed screws in calcaneal osteotomy. Foot Ankle Spec. 2018;11(5):420-4.

26. Shi G, Gross CE, Huh J, Parekn SG. Pantalar arthrodesis: surgical technique and review of literature. Duke Orthopaedic J. 2015;5(1):48-52. 